\title{
PENGARUH PERMAINAN CROSSWORD PUZZLE TERHADAP MOTIVASI DAN HASIL BELAJAR PESERTA DIDIK SD IT HARAPAN UMAT PURBALINGGA
}

\author{
Tri Rokhayati ${ }^{1 *}$, Tukiran Taniredja ${ }^{2}$, Akhmad Jazuli ${ }^{3}$ \\ 1)SD IT Harapan Umat Purbalingga \\ ${ }^{2,3}$ Magister Pendidikan Dasar Program Pascasarjana \\ Universitas Muhammadiyah Purwokerto \\ *tri.rokhayati@gmail.com
}

Received: 21 Februari 2020

Revised: 28 Februari 2020

Accepted: 29 Februari 2020

\section{ABSTRACT}

This research purpose to knowing affected of: 1) crosswords puzzle learning to learning motivation at third class in Harapan Umat Elementari School IT Purbalingga, 2) Crosswords puzzle learning to learning result at third class. Research method was experiment, with two group treatments that were control group and experiment group. Group control was $3 \mathrm{C}$ class and experiment group was $3 F$ class. Data using in this research were primary and secondary data. And then data be analyzed by Independent Sample t-test. Result of the research have shown: 1) crosswords puzzle learning significant affected to learning motivation at third class in Harapan Umat Elementary School IT Purbalingga; and 2) crosswords puzzle learning affected to learning result at third class.

Keywords: Crossword Puzzle; Learning Motivation; Learning Result

\section{PENDAHULUAN}

Pendidikan merupakan suatu sarana untuk mengembangkan segala potensi dasar manusia demi berkembanganya kemajuan suatu bangsa, dalam UndangUndang Dasar Negara Republik Indonesia tahun 1945 Pasal 31 ayat (1) disebutkan bahwa setiap warga negara berhak mendapatkan pendidikan. Undang-Undang Republik Indonesia No. 20 Tahun 2003 Pasal 5 juga menegaskan bahwa setiap warga negara berhak mendapatkan kesempatan meningkatkan pendidikan sepanjang hayat.

Upaya yang dilakukan demi berkembangnya potensi yang dimiliki peserta didik yaitu melalui proses pembelajaran, sehingga perlu adanya proses pendidikan yang berkualitas dengan menyediakan berbagai pengetahuan, keterampilan, penerapan ilmu yang sesuai dengan kemajuan zaman, dan pengelolaan pendidikan serta pembelajaran.

T. Rokhayati, T. Taniredja, dan A. Jazuli , Pengaruh Permainan Crossword Puzzle Terhadap Motivasi Dan Hasil Belajar Peserta Didik SD IT Harapan Umat Purbalingga 
Guru diharapkan dapat selalu mengatasi permasalahan yang dihadapi siswanya dalam proses pembelajaran. Ibrahim (2010:24) menjelaskan bahwa pada prinsipnya, dalam proses pembelajaran seorang guru juga harus bersifat sebagai fasilitator yang dapat memberikan dukungan terhadap terciptanya proses pembelajaran kondusif, agar siswa mampu belajar secara aktif menuju belajar yang mandiri.

Berdasarkan hasil pengamatan oleh peneliti di SD IT Harapan Umat Purbalingga, realita di lapangan guru masih melakukan pembelajaran konvensional yaitu guru bertindak sebagai penyampai materi dan siswa mencatat materi yang disampaikan oleh guru. Hasil pembelajaran tersebut kurang maksimal, hal ini dilihat dari kurangnya motivasi belajar dan hasil evaluasi belajar peserta didik setelah pembelajaran. Peserta didik kurang termotivasi dalam mengikuti pelajaran, ditandai dengan banyaknya peserta didik yang mengobrol bersama temannya dan asyik bermain sendiri daripada mencatat, yaitu sekitar 15 anak dari 30 peserta didik dalam kelas. Hasil belajar setelah dilakukan pembelajaran juga kurang memuaskan, di mana hanya 8 peserta didik yang mendapat nilai di atas KKM (>75) sedangkan sisanya 11 anak yang sesuai dengan KKM (75) dan 11 anak dibawah KKM. Kondisi seperti ini juga terjadi pada saat pembelajaran mata pelajaran IPS.

Motivasi belajar peserta didik dapat dilihat dari keaktifan siswa maupun kemampuan siswa dalam pembelajaran. Namun tidak semua peserta didik memiliki motivasi belajar yang tinggi. Faktanya, di SD IT Harapan Umat kabupaten Purbalingga, masih ditemukan beberapa peserta didik yang memiliki motivasi rendah dan hasil belajar yang rendah walaupun ada siswa yang mendapat nilai tinggi tapi masih didapatkan beberapa siswa yang mendapat nilai rendah dalam evaluasi kompetensi dasar setelah pembelajaran.

Berkaitan dengan masalah diatas, pada pembelajaran IPS ditemukan keragaman masalah sebagai berikut: keaktifan siswa dalam mengikuti pelajaran hampir tidak nampak, siswa jarang mengajukan pertanyaan, walaupun guru sering meminta agar siswa bertanya jika ada hal yang belum paham. Keaktifan dalam mengerjakan soal-soal latihan pada proses pembelajaran masih kurang, dan hasilnya juga belum memuaskan. 
Pembelajaran IImu Pengetahuan Sosial di SD haruslah menggunakan model pembelajaran yang dibantu dengan media pembelajaran sebagai alat pendukung dalam pelaksanaan pembelajaran. Suprijono (2012:46) mengemukakan bahwa model pembelajaran merupakan sebuah pola yang difungsikan sebagai acuan dalam membuat perencanaan pembelajaran di kelas, pelaksanaan pembelajaran di kelas, mengevaluasi dan merefleksi selama kegiatan belajar mengajar dilaksanakan. Tarigan (1986: 234) menyatakan bahwa pada umumnya para siswa menyukai permainan dan mereka dapat memahami dan melatih cara penggunaan kata-kata. Dengan menggunakan media peserta didik tidak merasa bosan selama mengikuti pembelajaran dan akan memperoleh hasil yang memuaskan, sehingga tujuan pembelajaran akan tercapai.

Dalam penelitian ini, penulis menggunakan permainan puzzle jenis crosswords (teka-teki silang). Pada TTS terdapat unsur permainan yang dapat menimbulkan kegairahan dan rasa senang dalam belajar tanpa harus berhadapan dengan situasi yang menjemukan (Haryono, 2013:128). Crossword puzzle adalah suatu media permainan dengan cara mengisi kotak-kotak dengan huruf-huruf sehingga membentuk kata yang dapat dibaca, baik secara vertikal maupun horisontal. Alasan penulis menggunakan model pembelajaran puzzle jenis crosswords (teka-teki silang) adalah untuk melatih ketelitian, kritis dalam berfikir dan menyenangkan.

\section{METODE PENELITIAN}

Tujuan penelitian ini untuk mengetahui hubungan antara permainan teka-teki silang dengan motivasi belajar dan hasil belajar IPS, dengan menilai perbedaan motivasi belajar dan hasil belajar. atau uji hipotesis tentang efek dari perawatan yang diberikan. Penelitian ini menggunakan eksperimen dengan desain kontrol posttest only, desain penelitian dengan eksperimen menggunakan dua kelompok, yaitu: 1) kelas kontrol adalah kelas dimana pembelajaran IPS tidak menggunakan teka-teki silang, dan 2) kelas eksperimen adalah kelas dimana pembelajaran IPS menggunakan teka-teki silang. 
Penelitian ini dilaksanakan di SD IT Harapan Umat Kabupaten Purbalingga di kelas tiga. Populasi dalam penelitian ini adalah semua siswa kelas $3 \mathrm{~F}$ sebanyak 27 anak dan kelas $3 \mathrm{C}$ sejumlah 27 anak.

Instrumen yang digunakan untuk menentukan teka-teki silang yang digunakan dalam pembelajaran menggunakan kuesioner. Sebelum penelitian dilakukan, instrumen yang digunakan untuk mengambil data aktual, terlebih dahulu mencoba uji coba instrumen, untuk menentukan tingkat validitas (validitas) dan reliabilitas (reliabilitas).

Uji validitas dalam penelitian instrumen tes kemampuan kognitif siswa menggunakan produk teknik uji validitas korelasi saat diusulkan oleh Pearson. Dalam penelitian ini validitas item dan angket (Korelasi Product Moment) menggunakan program SPSS 21.0 dengan uji Korelasi Bivarit. Item akan dikatakan valid jika nilai Sig. $<0.05$. Kriteria untuk menarik kesimpulan dengan, jika nilai korelasi ( $r$ hitung) lebih besar dari nilai $r$ tabel pada tingkat signifikansi $95 \%$ atau sama dengan 0,444 maka item dinyatakan valid dan jika lebih kecil dari 0,444 maka dinyatakan tidak valid. Item-item yang dinyatakan valid adalah valid digunakan sebagai pengukuran penelitian dan item-item yang dinyatakan tidak valid sehingga tidak layak sebagai pengukuran riset atau gugur.

Kemudian uji reliabilitas pada instrumen motivasi belajar dilakukan. Dalam penelitian ini analisis reliabilitas (Alpha Cronbach) menggunakan program SPSS 21.0. Pengambilan keputusan didasarkan pada koefisien Alpha Cronbach, yaitu jika Alpha Cronbach berada di atas batas minimum 0,70 atau> 0,70 maka instrumen tersebut memiliki keandalan yang baik.

Data penelitian yang digunakan berupa data motivasi belajar dan pembelajaran dengan teka-teki silang sebagai data primer. Sedangkan data sekunder berupa data hasil belajar mata pelajaran IPS di kelas 3F dan kelas 3C.

Kisi instrumen yang digunakan untuk mengukur metode pembelajaran Crossword Puzzle yang diadopsi dari Zaini (2007) disajikan pada Tabel 1. 
TUNJUK AJAR: JURNAL PENELITIAN ILMU PENDIDIKAN

Volume 3, Nomor 1, 2020

P-ISSN: 2615-062X

E-ISSN: 2622-3554

http://dx.doi.org/10.31258/ita.v3i1.65-76

Tabel 1. Kisi-kisi Instrumen Motivasi Metode Pembelajaran Crossword Puzzle

\begin{tabular}{|l|l|}
\hline Variabel & \multicolumn{1}{|c|}{ Indikator } \\
\hline \multirow{2}{*}{ Motivasi } & Dorong siswa untuk berkonsentrasi dalam belajar \\
\cline { 2 - 3 } & Merangsang siswa untuk lebih aktif dalam belajar \\
\cline { 2 - 2 } & Mengembangkan kemandirian siswa \\
\cline { 2 - 3 } & Menumbuhkan tanggung jawab dan disiplin siswa \\
\cline { 2 - 3 } & Memperdalam pemahaman siswa dalam belajar \\
\hline
\end{tabular}

Kriteria motivasi belajar menggunakan metode pembelajaran puzzle crosswords disajikan pada Tabel 2.Sedangkan kriteria hasil belajar menggunakan metode pembelajaran puzzle crosswords disajikan pada Tabel 3.

Tabel 2. Kriteria Motivasi Belajar Siswa

\begin{tabular}{cc}
\hline Kisaran & Motivasi Belajar \\
\hline $1,00-1,80$ & Sangat rendah \\
$1,80-2,60$ & Rendah \\
$2,60-3,40$ & Cukup tinggi \\
$3,40-4,20$ & Tinggi \\
$4,20-5,00$ & Sangat tinggi \\
\hline
\end{tabular}

Tabel 3. Kriteria Hasil Belajar Siswa

\begin{tabular}{cc}
\hline Kisaran & Hasil Belajar \\
\hline $0-50$ & Sangat rendah \\
$51-60$ & Rendah \\
$61-75$ & Cukup tinggi \\
$76-90$ & Tinggi \\
$91-100$ & Sangat tinggi \\
\hline
\end{tabular}

\section{HASIL DAN PEMBAHASAN PENELITIAN}

\section{Crosswords puzzle Terhadap Motivasi Belajar Peserta Didik}

Motivasi belajar siswa menggunakan metode pembelajaran Puzzle Crosswords disajikan pada Tabel 4. 
Tabel 4. Motivasi Belajar Siswa menggunakan metode pembelajaran Puzzle Crosswords

\begin{tabular}{ccc|cc}
\hline Motivasi & \multicolumn{2}{c|}{ Kelas Eksperimen } & \multicolumn{2}{c}{ Kelas Kontrol } \\
\cline { 2 - 5 } Belajar & Frekuensi & Persentase & Frekuensi & Persentase \\
\hline Sangat rendah & 0 & 0,00 & 0 & 0,00 \\
Rendah & 0 & 0,00 & 2 & 7,41 \\
Cukup tinggi & 5 & 18,52 & 9 & 33,33 \\
Tinggi & 18 & 66,67 & 13 & 48,15 \\
Sangat tinggi & 4 & 14,81 & 3 & 11,11 \\
\hline Total & 27 & 100,00 & 27 & 100,00 \\
\hline Average rating & 3,80 & Tinggi & 3,45 & Sedang \\
\hline
\end{tabular}

Sumber: Data primer diolah

Hasil analisis uji t dan analisis korelasi menunjukkan bahwa crosswords puzzle berpengaruh signifikan terhadap motivasi belajar peserta didik. Hasil analisis ditampilkan pada Tabel 5 dan 6 .

Tabel 5. Hasil Uji t Pengaruh Metode Pembelajaran Crosswords Puzzle terhadap Motivasi Belajar Siswa

\begin{tabular}{|c|c|c|c|c|c|c|c|}
\hline \multirow[t]{2}{*}{ Variabel } & \multirow[b]{2}{*}{$t$} & \multirow[b]{2}{*}{ df } & \multirow{2}{*}{$\begin{array}{l}\text { Sig. (2- } \\
\text { tailed) }\end{array}$} & \multirow{2}{*}{$\begin{array}{c}\text { Mean } \\
\text { Difference }\end{array}$} & \multirow{2}{*}{$\begin{array}{l}\text { Std. Error } \\
\text { Difference }\end{array}$} & \multicolumn{2}{|c|}{$\begin{array}{l}95 \% \text { Confidence } \\
\text { Interval of the } \\
\text { Difference }\end{array}$} \\
\hline & & & & & & Lower & Upper \\
\hline $\begin{array}{l}\text { Motivasi } \\
\text { Belajar }\end{array}$ & -2.791 & 52 & .007 & -12.333 & 4.419 & -21.200 & -3.467 \\
\hline
\end{tabular}

Tabel 6. Uji Korelasi Pengaruh metode pembelajaran crosswords puzzle terhadap Motivasi Belajar Siswa

\begin{tabular}{|c|c|c|c|}
\hline Variable & $\begin{array}{c}\text { Pearson Correlation } \\
\text { Coefficient }\end{array}$ & Sign. & Explanation \\
\hline Motivasi Belajar & 0,733 & 0,000 & Strong \\
\hline
\end{tabular}

Hasil ini membuktikan bahwa model pembelajaran crossword puzzle dapat menjadikan peserta didik aktif dalam proses pembelajaran, sehingga dengan penggunaan crosswords puzzle ini dapat meningkatkan motivasi belajar selain mengembangkan rasa saling bekerjasama antar peserta didik.

Model pembelajaran crossword puzzle ini juga dapat merangsang siswa lebih aktif dalam belajar, mengembangkan kemandirian siswa, memperdalam pemahaman siswa dalam belajar dan membina tanggung jawab dan disiplin siswa (Zaini dkk, 2007). Crosswords puzzle sangat mendidik, karena selain menyenangkan sehingga peserta didik lebih antusias dan lebih aktif dalam mengikuti pembelajaran dibandingkan yang pembelajarannya secara konvensional. 
Hal ini dapat dilihat dari data motivasi belajar siswa kelas $3 \mathrm{~F}$ sebagai kelas eksperimen di mana pada saat pembelajaran IPS menggunakan media crosswords puzzle, memiliki skor rata-rata 3,80 , sedangkan motivasi belajar siswa kelas $3 \mathrm{C}$ sebagai kelas kontrol di mana pada saat pembelajaran IPS menggunakan pembelajaran konvensional tanpa media pembelajaran apapun, memiliki skor ratarata 3,45. Di samping itu juga dikuatkan dengan perbedaan (selisih) rata-rata skor (mean) motivasi belajar antara kelas eksperimen yang pembelajarannya menggunakan crosswords puzzle dan kelas kontrol yang pembelajarannya secara konvensional, pada skor terendah adalah sebesar 3,467 dan pada skor tertinggi adalah sebesar 21,204. Selisi rata-rata skor tersebut cukup besar sehingga perbedaan motivasi kelas eksperimen dan kelas kontrol signifikan, yang berati pengaruh crosswords puzzle terhadap motivasi belajar adalah kuat.

Hasil penelitian ini didukung dengan hasil penelitian Masmu'ah, Hunaepi dan Laras Firdaus (2017) yang menunjukkan bahwa rata-rata motivasi belajar kelas eksperimen lebih baik daripada kelas kontrol (78,25\% dan 72,75\%). Dan uji-t menunjukkan bahwa media word square memiliki pengaruh terhadap motivasi belajar siswa, dengan tingkat keterpengaruhan sedang.

\section{Crosswords Puzzle Terhadap Hasil Belajar Peserta Didik}

Hasil belajar siswa menggunakan metode pembelajaran Puzzle crosswords disajikan pada Tabel 7.

Tabel 7. Hasil Belajar Siswa menggunakan metode pembelajaran Puzzle crosswords

\begin{tabular}{ccc|cc}
\hline \multirow{2}{*}{ Hasil Belajar } & \multicolumn{2}{c|}{ Kelas Eksperimen } & \multicolumn{2}{c}{ Kelas Kontrol } \\
\cline { 2 - 5 } & Frekuensi & Persentase & Frekuensi & Persentase \\
\hline Sangat rendah & 0 & 0,00 & 3 & 11,11 \\
Rendah & 0 & 0,00 & 1 & 3,70 \\
Cukup tinggi & 2 & 7,41 & 11 & 40,74 \\
Tinggi & 9 & 33,33 & 9 & 33,33 \\
Sangat tinggi & 16 & 59,26 & 3 & 11,11 \\
\hline Total & 27 & 100,00 & 27 & 100,00 \\
\hline Rata-rata & 92,22 & Tinggi & 73 & Sedang \\
\hline
\end{tabular}

Sumber: Data primer Diolah 
Tabel 8. Hasil Uji t Pengaruh Metode Pembelajaran Crosswords Puzzle terhdap Hasil Belajar Siswa

\begin{tabular}{|c|c|c|c|c|c|c|c|}
\hline \multirow{2}{*}{ Variabel } & \multirow[b]{2}{*}{$\mathrm{t}$} & \multirow[b]{2}{*}{$d f$} & \multirow{2}{*}{$\begin{array}{l}\text { Sig. (2- } \\
\text { tailed) }\end{array}$} & \multirow{2}{*}{$\begin{array}{c}\text { Mean } \\
\text { Difference }\end{array}$} & \multirow{2}{*}{$\begin{array}{l}\text { Std. Error } \\
\text { Difference }\end{array}$} & \multicolumn{2}{|c|}{$\begin{array}{l}95 \% \text { Confidence Interva } \\
\text { of the Difference }\end{array}$} \\
\hline & & & & & & Lower & Upper \\
\hline Hasil Belajar & -5.547 & 52 & .000 & $\begin{array}{l}-19.222 \\
\end{array}$ & 3.465 & -26.175 & -12.269 \\
\hline
\end{tabular}

Tabel 9. Uji Korelasi Pengaruh Metode Pembelajaran Crosswords Puzzle terhadap Hasil Belajar Siswa

\begin{tabular}{|c|c|c|c|}
\hline Variable & Correlation Coefficient & Sign. & Explanation \\
\hline Hasil Belajar & 0,824 & 0,000 & Very strong \\
\hline
\end{tabular}

Hasil analisis uji $\mathrm{t}$ dan analisis korelasi menunjukkan bahwa crosswords puzzle berpengaruh signifikan terhadap hasil belajar peserta didik. Hasil ini membuktikan bahwa model pembelajaran crossword puzzle dapat menjadikan peserta didik mudah memahami konsep dan materi pelajaran, sehingga dengan penggunaan crosswords puzzle ini dapatmeningkatkan hasil belajar. Hal ini sebagaimana yang dikemukakan oleh Zaini dkk (2007) bahwa kelebihan model pembelajaran crossword puzzle antara lain adalah memperdalam pemahaman siswa dalam belajar dan membina tanggung jawab dan disiplin siswa.

Penggunaan crossword puzzle (teka-teki silang) dalam pembelajaran akan mempermudah siswa untuk mengingat dan memahami konsep-konsep yang terkandung dalam materi pelajaran,sehingga berpengaruh terhadap hasil belajar yang dicapai oleh peserta didik. Pernyataan ini dikuatkan dengan data hasil belajar siswa kelas 3 yang diteliti. Hasil belajar siswa kelas eksperimen di mana pada saat pembelajaran IPS menggunakan media crosswords puzzle, memiliki nilai rata-rata 92,22. Hasil belajar siswa kelas kontrol di mana pada saat pembelajaran IPS menggunakan pembelajaran konvensional tanpa media pembelajaran apapun, memiliki nilai rata-rata 73,00 . Di samping itu juga dikuatkan dengan perbedaan (selisih) skor yang signifikan. Dalam output perbedaan (selisih) rata-rata skor (mean) hasil belajar antara kelas eksperimen yang pembelajarannya menggunakan crosswords puzzle dan kelas kontrol yang pembelajarannya secara konvensional, yang menunjukkan bahwa skor hasil belajar kelas eksperimen lebih tinggi dari kelas 
kontrol yaitu pada skor terendah sebesar 12,269 dan pada skor tertinggi sebesar 26,175 .

Hasil penelitian ini menunjukkan secara empiris bahwa pembelajaran crosswords puzzle berpengaruh terhadap hasil belajar. Hasil ini sesuai dengan pendapat Muhibin Syah (2008:139) yang menyatakan bahwa faktoryang dapat mempengaruhi hasil belajar peserta didik di sekolah salah satunya adalah faktor pendekatan belajar (approach to learning), salah satunya adalah penggunaan model pembelajaran crosswords puzzle.

Media pembelajaran yang digunakan oleh guru yaitu crosswords puzzle dalam pembelajaran maa pelajaran IPS telah terbukti secara empiris dapat mempengaruhi dan meningkatkan motivasi belajar siswa dalam memahami dan menerimaa materi pelajaran yang disampaikan oleh guru. Berdasarkan hasil penelitian di atas, maka dapat disimpulkan bahwa media pembelajaran crosswords puzzle yang dilakukan di SD IT Harapan Umat Purbalingga sudah baik, hal ini dapat dilihat dari penggunaan permainan crosswords puzzle yang digunakan oleh guru dalam menyampaikan materi dalam proses pembelajaran IPS. Hal ini berarati guru kelas 3 di SD IT Harapan Umat Purbalingga sudah mengupayakan dan mengembangkan media pembelajaran demi meningkatkan kualitas pendidikan yang lebih baik bagi siswa. Hal ini dilihat dari skor motivasi belajar siswa kelas eksperimen yang lebih tinggi dari kelas konrol, sehingga dapat dikatakan bila penggunaan media crosswords puzzle juga memberikan kontribusi dalam meningkatkan motivasi belajar siswa yang tergolong dalam kategori tinggi dalam pembelajaran maa pelajaran IPS. Dimana hal ini berarti bahwa dalam pemberian materi pembelajaran untuk mencapai tujuan pembelajaran yeng telah ditetapkan, didukung dengan media pembelajaran yang memadai dan tepat yang dapat memotivasi siswa untuk mengikuti proses pembelajaran.

Media pembelajaran crosswords puzzle yang digunakan oleh guru dalam pembelajaran maa pelajaran IPS telah terbukti secara empiris dapat mempengaruhi dan meningkatkan hasil belajar siswa karena siswa mudah memahami dan menerimaa materi pelajaran yang disampaikan oleh guru. Berdasarkan hasil penelitian di atas, maka dapat disimpulkan bahwa media pembelajaran crosswords 
puzzle yang dilakukan di SD IT Harapan Umat Purbalingga adalah baik. Hal ini berarati guru kelas 3 di SD IT Harapan Umat Purbalingga sudah mengupayakan dan mengembangkan media pembelajaran demi meningkatkan kualitas pendidikan yang lebih baik bagi siswa. Hal ini dilihat dari nilai hasil belajar siswa kelas eksperimen yang sangat tinggi, shingga dapat dikatakan bila penggunaan media crosswords puzzle juga memberikan kontribusi dalam meningkatkan hasil belajar siswa yang tergolong dalam kategori sangat tinggi dalam pembelajaran maa pelajaran IPS. Hal ini juga berarti bahwa pemberian materi pembelajaran untuk mencapai tujuan pembelajaran yeng telah ditetapkan, didukung dengan media pembelajaran yang memadai dan tepat sehingga dapat meningkatkan hasil belajar siswa.

Berdasarkan hasil pengujian hipotesis, yaitu terdapat pengaruh variabel media pembelajaran crosswords puzzle terhadap varaibel motivasi belajar dan hasil belajar siswa kelas 3 di SD IT Harapan Umat Purbalingga, .maka hasil penelitian menunjukkan bahwa media pembelajaran merupakan salah satu dari beberapa faktor yang dapat mempengaruhi motivasi belajar dan hasil belajar siswa. Inti dari penelitian ini adalah penggunaan media pembelajaran crosswords puzzle dapat meningkatkan motivasi belajar dan hasil belajar siswa apabila dilakasanakan dengan baik, sehingga penelitian ini dapat dikembangkan untuk mengetahui penggunaan media pembelajaran di sekolah lain.

\section{SIMPULAN}

Hasil analisis dan pembahasan penelitian yang telah dilakukan dan telah dijelaskan pada bab sebelumnya di atas, maka dapat ditarik kesimpulan sebagai berikut:

1. Crosswords puzzle berpengaruh signifikan terhadap motivasi belajar peserta didik. Pengaruh tersebut ditunjukkan dengan adanya perbedaan yang signifikan pada skor motivasi belajar kelas eksperimen yang lebih tinggi dibanding skor motivasi belajar kelas kontrol.

2. Crosswords puzzle berpengaruh signifikan terhadap hasil belajar peserta didik. Pengaruh tersebut ditunjukkan dengan adanya perbedaan yang signifikan pada 
nilai hasil belajar kelas eksperimen yang lebih tinggi dibanding nilai hasil belajar kelas kontrol.

3. Guru di SDIT Alam Harapan Umat Purbalingga khususnya guru kelas 3 dapat menggunakan permainan Crosswords puzzle dalam pelaksanaan pembelajarannya untuk meningkatkan motivasi belajar peserta didik.

4. Guru di SDIT Alam Harapan Umat Purbalingga khususnya guru kelas 3 dapat menggunakan permainan Crosswords puzzle dalam pelaksanaan pembelajarannya untuk meningkatkan hasil belajar peserta didik.

5. Permainan Crosswords puzzle dapat meningkatkan motivasi dan hasil belajar peserta didik, hendaknya SDIT Alam Harapan Umat Purbalingga lebih mendorong dan memfasilitasi para guru agar kreatif dan inovatif dengan menggunakan berbagai media pembelajaran yang tepat dalam melaksanakan pembelajarannya.

\section{DAFTAR PUSTAKA.}

Cagatay, Gulsen \& Demircioglu, Gokhan. 2013. The Effects of Jigsaw-i Cooperative Learning Technique on Students' Understanding About Basic Organic Chemistry Concepts. The International Journal of Educational Researches. 4(2): 30-37.

Hanifah. 2009. Model pembelajaran di sekolah dasar. Sumedang: UPI Press.

Ibnatul Izzati, Choirul Huda, Qoriati Mushafanah. 2017. Keefektifan Model Pembelajaran Word Square Berbantu Media Puzzle Pada Mata Pelajaran IPS SD. Profesi Pendidikan Dasar. Vol. 4, No. hal: $106-112$.

Rahmah, Ana Miftakhrul. 2012. "Upaya Peningkatan Hasil Belajar Siswa Melalui Metode Card Sort pada Mata Pelajaran IPS Kelas IV di MI Muhamadiyah Sleman". Skripsi. UIN Sunan Kalijaga..

Siti Juwersih. 2015. Peningkatan Motivasi dan Hasil Belajar Siswa Materi Pembagian Bumi Atas Benua dan Samudera Melalui Model Jigsaw dengan Permainan Puzle. Jurnal Didaktika Islamika. Volume 5 Nomor 1. Hal. 125140.

Sri Haryati Oktavia dan Zakir Has. 2017. Pengaruh metode Pembelajaran Crossword Puzzle Terhadap Hasil Belajar mata pelajaran IPS Terpadu di Kelas VIII SMP Bukit Raya Pekanbaru. Jurnal Pendidikan Ekonomi Akuntansi FKIP UIR. Vol 5 No 1. Hal. 43-57. 
TUNJUK AJAR: JURNAL PENELITIAN ILMU PENDIDIKAN

Volume 3, Nomor 1, 2020

P-ISSN: 2615-062X

E-ISSN: 2622-3554

http://dx.doi.org/10.31258/jta.v3i1.65-76

Sugiyono. 2015. Metode Penelitian Kuantitatif Kualitatif R\&B. Bandung:. Alfabeta.

Sugiyono. 2008. Statistik untuk Penelitian. Bandung:. Alfabeta.

Suprijono, A. 2012. Cooperative Learning Teori dan Aplikasi Paikem. Yogyakarta: Pustaka Belajar.

Zaini, Hisyam. 2007. Psikologi Pendidikan dengan Pendekatan Baru. Bandung: PT. Remaja Rosdakarya. 